\title{
Care Practices that Promote Normal Birth
}

\section{\#2: Freedom of Movement throughout Labor}

\author{
Lamaze International Education Council \\ Principal authors: Teri Shilling, MS, IBCLC, CD (DONA), LCCE, FACCE \\ Joyce DiFranco, RN, BSN, LCCE, FACCE \\ With commentary by Penny Simkin, PT, CD (DONA)
}

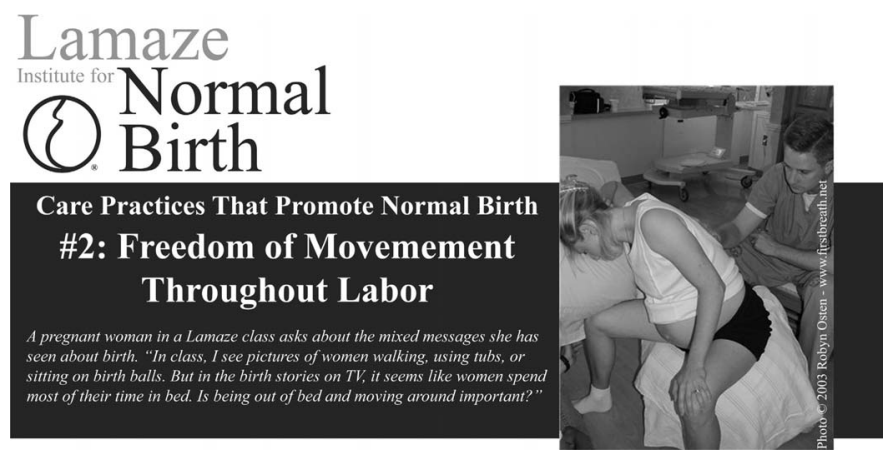

\begin{abstract}
In this position paper-one of six care practice papers published by Lamaze International and reprinted here with permission-the benefit of allowing freedom of movement throughout labor is discussed and presented as an evidence-based practice that helps promote, protect, and support normal birth. The paper is written for childbearing women and their families. The accompanying commentary-written by a well-known author of numerous articles and books on childbirth-compares the activities of women in two birthing environments: the conventional medicalized setting and the unconventional naturalistic setting. Reasons why women may not move in labor are presented. Lamaze International encourages women to use movement in labor in order to make labor more comfortable and more efficient.

Journal of Perinatal Education, 13(2), 11-15; normal birth, labor, care practices, childbirth education.
\end{abstract}

A study published in The New England Journal of Medicine in 1998 looked at the effects of walking during labor. Although in this study the labors of women who walked were not shorter, the women who walked were so satisfied that $99 \%$ of them stated that they would like to walk again during future labors. 


\section{Lamaze \\ (2) Northal}

\section{Care Practices That Promote Normal Birth \#2: Freedom of Movemement Throughout Labor}

A pregnant woman in a Lamaze class asks about the mixed messages she has seen about birth. "In class, I see pictures of women walking, using tubs, or sitting on birth balls. But in the birth stories on TV, it seems like women spend most of their time in bed. Is being out of bed and moving around important?"

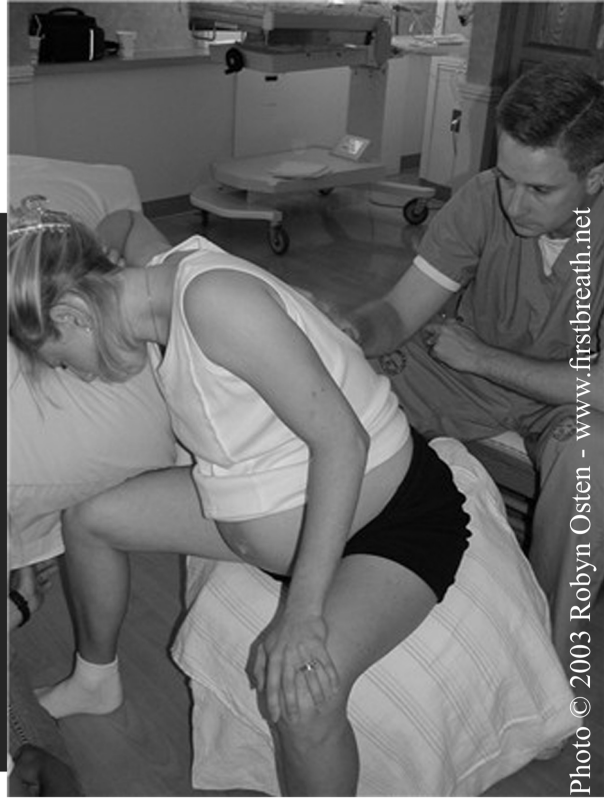

Freedom of movement is important in making the birth of your baby easier. It's the best way for you to use gravity to help your baby come down, and to increase the size and shape of your pelvis. ${ }^{1}$ It allows you to respond to pain in an active way, and it may speed up the labor process.

In contrast to what is seen on popular TV shows in the United States, pictures from throughout history and across varying cultures show women in many different positions for labor. According to the Cochrane Pregnancy and Childbirth Group, a respected worldwide source of information regarding evidence-based care, studies demonstrate that a laboring woman's ability to move and choose her own position is most likely beneficial. ${ }^{2}$ Activity provides distraction from discomfort, a sense of greater personal freedom, and a chance to release the muscle tension that can increase pain. One study has shown that, when laboring on their own without restriction, women find many positions that are comfortable. They change positions more frequently as they move toward the actual birth. ${ }^{3}$ Without direction and when listening to her own body signals, a woman will move between standing, crouching, squatting, sitting, and kneeling positions.

\section{Why Movement Helps}

The uterus responds to movement by working more efficiently. ${ }^{4}$ The positions a woman chooses for comfort also often help her baby progress through the birth canal. Studies have shown that position changes may be useful in encouraging the baby to rotate and pass through the pelvis as needed for labor to progress. ${ }^{5,6}$ This may be particularly useful when the baby has entered the mother's pelvis in a posterior (the back of the baby's head facing the mother's back) position rather than the more favorable anterior (the back of the baby's head facing the front of the mother's abdomen) position. When labor slows, a change in position will often help it "find its rhythm" again.

At times during labor a woman may tire and need to rest in a comfortable position. However, according to a 2003 study published in Nursing Research, a laboring woman's lower back pain is significantly worse in active labor when she is in a supine (lying-down) position. ${ }^{7}$ Every birthing facility should therefore provide many options that allow a woman to move and change position. A woman should be able to rest in a rocking chair, on a birth ball, or in a tub of water. She may need the comfort of a beanbag or armless chair in which she can sit backward, leaning forward on a pillow placed over the back of the chair. A woman may want to slow dance to music or use a rebozo (a Mexican shawl) to help with movement and positioning. There should be a safe walking area both inside and outside the birthing facility, whether the facility is a hospital, a birth center, or a woman's home.

A study published in The New England Journal of Medicine in 1998 looked at the effects of walking during labor. Although in this study the labors of women who walked were not shorter, the women who walked were so satisfied that $99 \%$ of them stated that they would like to walk again during future labors. ${ }^{8}$

\section{Practicing Helpful Positions and Movements}

In childbirth classes, a woman and her partner will practice 
various positions and movements. She will practice forward-leaning positions that encourage the baby to enter the pelvis in a position that makes labor and birth easier. These forward-leaning positions should be used during the last weeks of pregnancy as well as during labor, especially if a woman experiences severe back pain. ${ }^{9}$ Childbirth classes also teach a woman how to rock her pelvis and use the lunge, the stomp/squat, slow dancing, the knee/chest position, and stair climbing as key movements during labor. Practicing with aids such as the birth ball and rebozo make it easier for women to use them in labor.

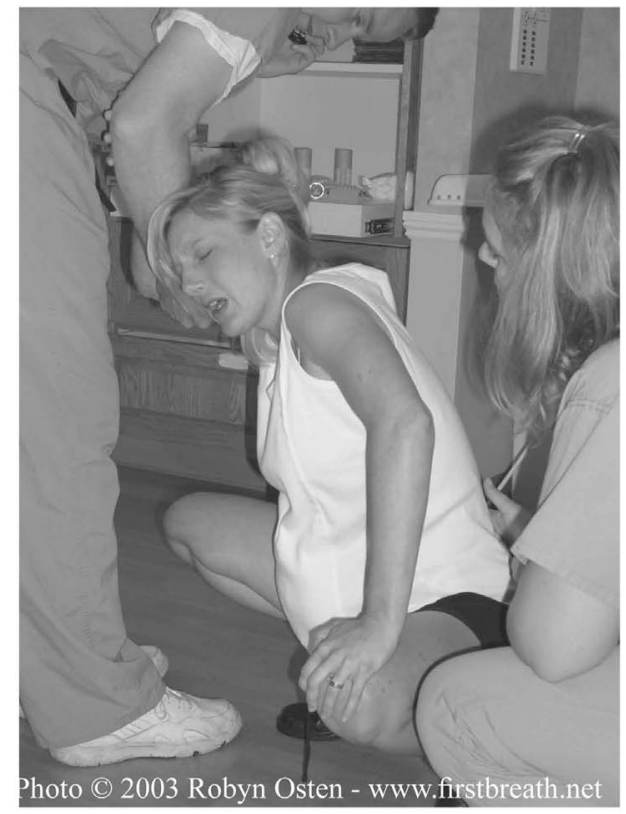

\section{Reasons Why Women May Not Move in Labor}

Although a hospital may not have policies that restrict a laboring woman to bed, the routine use of continuous electronic fetal monitoring, IVs, drugs to induce or augment labor, and epidurals do limit her movement and confine her to bed. Indeed, when American women were asked why they did not walk around during labor, the number 1 answer they gave was "Connected to things." If the comfort of laboring women is to be improved, and if normal birth is to be supported, interventions such as fetal monitoring and IVs should be used only when complications make them necessary. When it is medically necessary to use these interventions, women should be guided to continue to move in whatever way they can. For example, women could be supported in changing from side-lying to leaning over the back of the bed or on the squat bar.

\section{Recommendations of Lamaze International}

Freedom of movement is a major component of pain management. Like many women throughout the world, you can use movement to make labor more comfortable and more efficient. While there is no single ideal labor position, your freedom to choose and respond in your own way is critical. "Perhaps the biggest consideration .... is how a mother feels about her own freedom to choose when and how much to move around, sit, stand, rock on hands and knees, or assume any other positions. Often a mother will instinctively assume a position that favors faster, more effective labor." 11 Birth is an active process, and, without restrictions, you will respond to make birth easier for yourself and your baby.

\section{References}

1. Simkin, P., \& Ancheta, R. (2000). The labor progress handbook. Malden, MA: Blackwell Science.

2. Enkin, M., Keirse, M.J., Neilson, J., Crowther, C., Duley, L., Hodnett, E., et al. (2000). A guide to effective care in pregnancy and childbirth. New York: Oxford University Press.

3. Carlson, J.M., Diehl, J.A., Sachtleben-Murray, M., McRae, M., Fenwick, L. \& Friedman, E.A. (1986). Maternal position during parturition in normal labor. Obstetrics \& Gynecology, 68(4), 443-447.

4. Roberts, J.E., Mendez-Bauer, C., \& Wodell, D.A. (1983). The effects of maternal position on uterine contractility and efficiency. Birth, 10, 243-249.

5. Fenwick, L., \& Simkin, P. (1987). Maternal positions to prevent or alleviate dystocias in labor. Clinical Obstetrics \& Gynecology, 30(1), 83-89.

6. Simkin, P. \& O'Hara, M. (2002). Nonpharmacologic relief of pain during labor: Systematic reviews of five methods. American Journal of Obstetrics and Gynecology, 186(5, supplement), S127-S159.

7. Adachi, K., Shimada, M., \& Usai, A. (2003). The relationship between the parturient's positions and perceptions of labor pain intensity. Nursing Research, 52(1), 47-51.

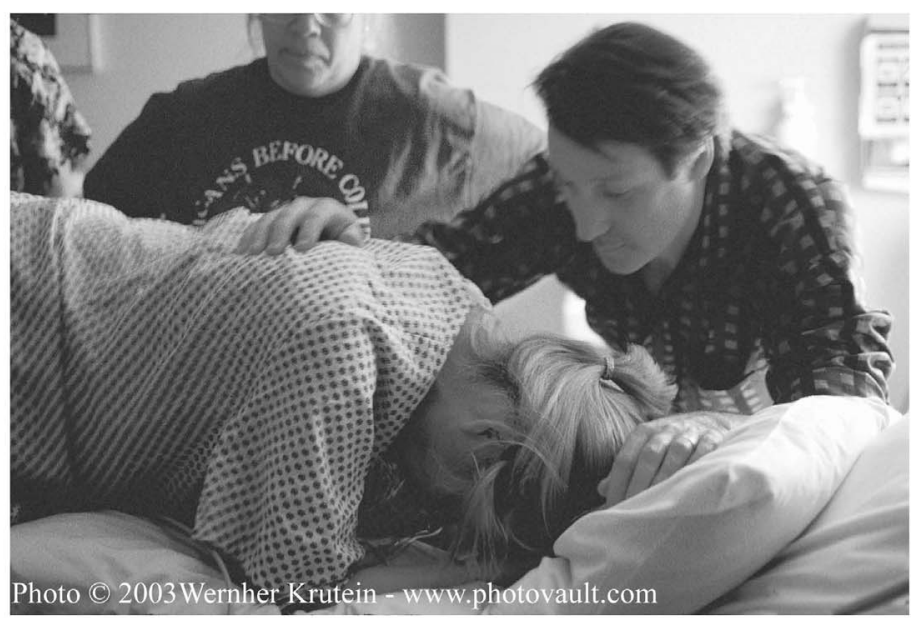


8. Bloom, S.L., McIntire, D.D., Kelly, M.A., Beimer, H.L., Burpo, R.H., Garcia, M.A., et al. (1998). Lack of effect of walking. The New England Journal of Medicine, 339(2), 117-118.

9. Scott, P. (2003). Sit up and take notice! Positioning yourself for a better birth. Tauranga, New Zealand: Great Scott Publications.

10. Declerq, E.R., Sakala, C., Corry, M.P., Applebaum, S., \& Risher, P. (2002). Listening to mothers: Report of the first national U.S. survey of women's childbearing experiences. New York: Maternity Center Association.

11. Kroeger, M. (2004). Maternal position in labor, birth, and breastfeeding, page 70 in Impact of birthing practices on breastfeeding: Protecting the mother and baby continuum. Sudbury, MA: Jones and Bartlett Publishers.

\section{Developed by the Lamaze International Education Council}

Principal Authors:

Teri Shilling, MS, IBCLC, CD(DONA), LCCE, FACCE

Joyce DiFranco, RN, BSN, LCCE, FACCE

Contributors and Reviewers:

Debby Amis, RN, BSN, CD(DONA), LCCE, FACCE

Elena Carrillo de Reyes, CD(DONA), LCCE, FACCE

Diana Chiaverini, RN, MEd, LCCE, FACCE

Jeannette Crenshaw, RN, MSN, IBCLC, LCCE, FACCE

Caroline Donahue, RN, MA, LCCE, FACCE

Jeanne Green, MT, CD(DONA), LCCE, FACCE

Judith Lothian, RN, PhD, LCCE, FACCE

Michele Ondeck, RN, MEd, IBCLC, LCCE, FACCE

Sandra Steffes, RN, MS, LCCE, FACCE

(C) 2003 Lamaze International. "Lamaze" is a registered trademark of Lamaze International, Inc. Paper may be copied and distributed as long as attribution to Lamaze International is included. For more information about Lamaze International, visit our Web site at http://www.lamaze.org or call (800) 368-4404 or (202) 367-1128. 


\section{Commentary by Penny Simkin, PT, CD (DONA)}

The birthing environment dictates whether, how, where, and when a laboring woman moves around. Consider the following two scenarios that portray healthy women in contrasting birthing environments.

The first is the more common scenario in North America, today-a hospital room where induction or augmentation of labor and epidural analgesia are the norm. The room features a narrow, multiposition electronic bed on wheels as its central focus, with elastic belts arranged neatly so that electronic fetal monitoring can be initiated immediately upon the woman's arrival. The bed is surrounded by safety equipment: electronic fetal monitor, automatic blood pressure machine, automatic thermometer, IV pole hung with bags of fluid, an infusion pump, epidural syringe, a patient-controlled analgesia device, oxygen and suction devices, a fully equipped and heated newborn care cart, epidural cart, delivery cart, and emergency-call devices. All of these items are necessary, even for healthy women with induction and epidural. Even though some amenities are provided for the woman (shower, bathtub, rocker, birthing ball, squatting bar, and beverages), their use is often restricted, discouraged, or impossible.

Choices for positions used by the women depend on the nurses' assessments of the effects of the position on fetal well-being. Sometimes, the mother's chosen position makes it difficult to obtain a good fetal heart rate tracing; sometimes, the baby's heart rate slows when the woman is in a particular position. The nurse must then ask her to change to a position that is free of such drawbacks. In fact, as normal an activity as rolling over or sitting up becomes a medical decision in such an environment. The choices of positions are restricted to supine, semireclining, and side-lying positions in bed. Brief trips to the bathroom in early labor are usually allowed; however, these interruptions are awkward because the woman must be disconnected from the monitor and unwound from the IV catheter in order for her to push the IV pole into the bathroom. Of course, after the epidural, she will rely on catheterization to empty her bladder, so that trips to the bathroom become unnecessary. She may also require help in shifting her position in bed. How far we have come from giving birth "as nature intended.”
Contrast that scenario with a birth setting (home, birth center, small or low-tech hospital) where the woman is the central figure in a process that is allowed to unfold at its own pace under the watchful eye and patient presence of her midwife or midwife-like doctor. Epidurals and induction are reserved for problems. Freedom to move is considered essential to the woman's comfort and well-being, as well as for the progression of labor. In fact, it is not unusual to spot a woman strolling around or outside her room, stroking her bare belly, moaning rhythmically and powerfully, and accompanied by her partner or doula or midwife (or all three), moaning along with her. One of them may carry a pillow to place on the floor as the woman drops to her knees for each contraction. Someone else may carry a shawl, so that when the woman says, "Cold!" the shawl is quickly placed around her shoulders, only to be cast off in a minute or two. Every time she reaches a particular chair on her path, the woman may kneel on the seat and lean over the back for a contraction-shawl still draped over her shoulders - then resume her loud and powerful stroll. She is the queen, directing all activities with support and nurturing by those in her entourage.

We witness scenes like this over and over again in settings where the atmosphere is peaceful and nondirective and women are free to find their own best way to labor. They make good use of positional aids, baths, and the people around them. Staff members are accustomed to the sights, sounds, and movements of normal birth, and they are comfortable taking their lead from the woman while unobtrusively observing fetal and maternal well-being.

The freedom to move spontaneously is fundamental to maintaining normalcy during childbirth. Take away the freedom to move and you take away everything. Then, as we have already seen, birth must be reinvented-what replaces it is a poor substitute for the real thing.

With its publication of Six Care Practices that Promote Normal Birth, Lamaze International is bringing back the real thing.

PENNY SIMKIN lives in Seattle, Washington, and has specialized in childbirth education, counseling, and support since 1968. She is author or co-author of numerous books and articles on childbirth. 